\title{
O gênero jornalístico notícia impressa: dialogismo, avaliatividade e estilo
}

\author{
Rodrigo Acosta ${ }^{1}$
}

\section{Resumo}

O presente estudo busca apresentar discussões sobre a construção lingüístico-textual (dimensão verbal) do gênero jornalístico notícia impressa. Para tanto, revisitamos as pesquisas de Bakhtin e o Círculo, assim como de seus interlocutores contemporâneos. Analisamos cerca de 40 notícias retiradas de quatro jornais diferentes do Brasil. Os resultados demonstram a construção dialógica, valorativa e ideológica das notícias na esfera do jornalismo impresso.

Palavras-chave: Gênero jornalístico notícia. Dialogismo. Valoração.

\begin{abstract}
The present paper aims at discussing about the text-linguistic (verbal dimension) construction of news report genre. To do it, we reviewed Bakhtin's studies as well as his contemporary researchers' ones. We analyzed 40 news from 4 different Brazilian newspapers. The findings show a dialogical, evaluative and ideological construction of news in contemporary newspapers.
\end{abstract}

Keywords: News report discourse genre. Dialogism. Appraisal.

\section{Introdução}

Neste estudo, abordamos a construção lingüística (dimensão verbal) do gênero jornalístico notícia, a partir da análise das regularidades verbo-textuais sob a perspectiva do dialogismo e da valoração. Para tanto, revisitamos conceitos, categorias e fundamentações da Análise Dialogica de Discurso (doravante, ADD), de base bakhtiniana (BAKHTIN, 1926; 1981; 1989; 1993; 1998; 2003; 2006) que perpassam a discurvidade do gênero, da sua constituição e de seu funcionamento. Nesta investigação, portanto, inicialmente, retomamos a situação social de interação da notícia por meio de discussões que se orientam para os horizontes temático e valorativo (axiológico), assim como para as relações dialógicas que orientam o(s) sentidos(s) da notícia e para sua composicionalidade textual. Por fim,

\footnotetext{
${ }^{1}$ Doutorando UFSC. Mestre em Lingüística pela Universidade Federal de Santa Catarina, Brasil (2008). Professor Assistente da Universidade Federal do Rio Grande do Norte , Brasil E-mail: drigo_acosta@yahoo.com.b
} 
apresentamos as projeções estilístico-composicionais (verbais) do gênero, a partir da identificação de suas regularidades relativamente estáveis na esfera social do jornalismo impresso quanto ao tema e ao projeto discursivo.

\section{0 referencial e o corpus da pesquisa: a visão discursiva frente aos dados}

Os dados da pesquisa ${ }^{\mathrm{i}}$ constituem-se em 40 notícias, das quais 10 são do Jornal Zero Hora (RS), 10 do Jornal Diário Catarinense (SC), 10 do Jornal Correio do Povo (RS) e 10 do

Jornal O Estado de S. Paulo - 'Estadão' (SP) publicadas nos cadernos Geral e Nacional, durante o período de 10 a 20 de dezembro de 2007.

A pesquisa, situando-se no horizonte do Círculo de Bakhtin, buscou, em adição, relacionar as fundamentações da ADD (BAKHTIN ${ }^{\mathrm{ii}}$, 1926; 1981; 1989; 1993; 1998; 2000; 2002; 2003; 2006); Brait (2006); Rodrigues (2001); Rojo (2005; 2007) com a Teoria do Jornalismo com base em Alsina (1993); Breton (2003); Cornu (1998); Fontcuberta (1993); Katz (1993); Lage (2005); e Traquina (2001). A partir dessa perspectiva, o presente artigo objetiva explanar sobre a construção lingüística da dimensão verbal do gênero notícia, apresentando uma análise descritivo-interpretativa das regularidades enunciativo-discursivas que engendram e se engendram na constituição e no funcionamento desse gênero.

O artigo assim está organizado (a) seção que aborda a explicação sobre o horizonte temático do gênero; (b) seção que procura apresentar as diferentes relações dialógicas que se engendram no funcionamento do gênero notícia na esfera jornalística impressa; (c) seção que explica o projeto sociodiscursivo das notícias e (d) seção que introduz as considerações finais dessa investigação.

\section{0 horizonte temático do gênero notícia: objeto de discurso e efeitos de sentido}

Sob a perspectiva da ADD, podemos afirmar que o horizonte temático (o tema) do enunciado refere-se ao seu objeto de discurso e determinados sentidos (a partir de relações entre outros enunciados) que nesse enunciado se materializam. Com isso, para Bakhtin (1998; 2003), os gêneros apresentam-se engendrados em horizontes temáticos específicos que se definem a partir das inter-relações entre objeto e projeto discursivos, orientações e posicionamentos de sentidos (enunciados) e posições dos interlocutores. 
No plano da notícia, o horizonte temático caracteriza-se pela contemporaneidade, efemeridade e proximidade tempo-espacial dos fatos e dos acontecimenos a serem noticiados. A seleção dos fatos a serem reportados, assim como a ação dos critérios de noticiabilidade perpassam e se entrecruzam dialogicamente no horizonte temático das notícias. A contemporaneidade midiática identifica o fato/ acontecimento e o reenuncia para a construção discursiva da notícia, posto que

\footnotetext{
O discurso das mídias se fundamenta no presente da atualidade, e é a partir desse ponto de referência absoluto que elas olham timidamente para ontem e para amanhã, sem poder dizer muita coisa a respeito. Não raro fazem o que o meio profissional chama de perspectivação , que não pode trazer, no entanto, explicações históricas. (CHARAUDEAU, 2006, p. 134).
}

As notícias foram analisadas, primeiramente, a partir da identificação de determinadas temáticas. Retoma-se que as seções cujas notícias foram analisadas são a seção 'Geral' no Correio do Povo, Diário Catarinense e Zero Hora; e a seção 'Metrópole’ ou 'Cidades’ no jornal $O$ Estado de S. Paulo. Para a apresentação das regularidades do gênero serão apresentados a temática identificada e o número de ocorrências/incidências para detalhamento dos dados em discussão. Para tanto, revisitamos as fudamentações epistemológicas da ADD, retomando as discussões sobre gêneros do discurso, enunciados, e conteúdo temático. Nos jornais, ao longo das seções analisadas, foram identificadas temáticas que se orientavam para discussões relativas a determinados horizontes conforme gráfico em anexo (Cf. anexo 01).

A partir do levantamento dos horizontes temáticos que as notícias dos jornais selecionados apresentam, observamos que o jornal Zero Hora possui uma recorrência de temas nas áreas de festividades, educação e trânsito. O Correio do Povo, semelhante a Zero Hora, noticia festivais e comemorações diversas (seja de âmbito local ou nacional), bem como apresenta grande incidência de notícias voltadas às políticas local e nacional. $\mathrm{O}$ jornal $O$ Estado de S. Paulo, por sua vez, possui um direcionamento temático predominante nos assuntos sobre violência, ações da polícia e questões voltadas à justiça.

O Diário Catarinense, no período analisado, apresentou temas sobre festivais e comemorações locais ou estaduais, notícias sobre política local, saúde e trânsito. Em adição, o que se apresenta saliente nas investigações sobre os temas predominantes são as diversas ressonâncias temáticas que se entrecruzam na construção do gênero notícia. Essas ressonâncias caracterizam-se pelos cruzamentos ou atravessamentos de temáticas que se engedram no discurso desse gênero. 
Por exemplo, as temáticas 'polícia', ‘justiça' e violência' geralmente são agrupamentos que se inter-relacionam, assim como ‘trânsito’ e ‘violência', 'direitos e deveres do cidadão’, ‘justiça’ e ‘solidariedade’, entre outras temáticas que se interligam. O importante é observar que nas diversas notícias selecionadas, poucas foram as que apresentaram temáticas específicas e limitadas, sem qualquer ressonância de cruzamentos temáticos. A dialogicidade é constitutiva do horizonte temático, à medida que os cruzamentos de temas são, em adição, estratégias de construção das informações, legitimando-as, regularizando-as e valorando-as na materialidade do gênero notícia.

Em outras palavras, os entrecruzamentos temáticos excercem o papel de legalizador da notícia, isto é, apresentam-se ora como (a) discursos regularizadores das informações, à medida que consubstanciam o tema tratado (apresentando outras informações ou dados coerentes ao assunto em questão), ora como (b) discursos autoritativos (apresentando outras informações, dados ou relatos que servem como argumentos de autoridade na sustentação das notícias apresentadas, autorizando-as a serem legítimas).

Outra questão que observamos é que os entrecruzamentos (ressonâncias, cruzamentos ou atravessamentos) temáticos estão intimamente relacionados com os efeitos de credibilidade ou efeitos de verdade que o discurso da notícia objetiva alcançar. A busca por autenticidade, legitimidade e veracidade apresentam-se como objetivos centrais das notícias. Com isso, as ressonâncias temáticas que resultam dos diversos cruzamentos de temas que se engendram são procedimentos ou estratégias de construção desses efeitos.

Dessa forma, apreender o horizonte temático e as diferentes inter-relações dialógicas que se constroem nessa instância do gênero, é compreender a primeira visada (projeto discursivo) das diversas que se conjugam à constituição e ao funcionamento da notícia. Para Charaudeau (2006, p. 88-89),

\footnotetext{
No discurso da informação, entretanto, não se trata de verdade em si, mas da verdade ligada à maneira de reportar os fatos: não é bem das condições de emergência da verdade que se trata, mas sim das condições de veracidade. À instância midiática cabe autenticar os fatos, descrevê-los de maneira verossímil, sugerir as causas e justificar as explicações dadas. Autenticar é uma atividade que consiste em fazer crer na coincidência sem filtragem nem falsas aparências, entre o que é dito e os fatos descritos.
}

Assim, os temas (ou seja, o tema enquanto materialidade discursiva) que foram identificados nas notícias apresentaram-se como (a) horizontes ou ressonâncias temáticas, especificando e determinando diversos assuntos a serem tratados; (b) discursos regularizadores, consubstanciando o tema tratado, apresentando-se sob a forma de 
informações, dados ou relatos adicionais e (c) discursos autoritativos, à medida que se apresentam como informações adicionais de autoridade, sustentando a legitimidade da notícia. Os jornais, portanto, apresentam-se construídos por diversos temas que significam e legitimam as informações apresentadas acerca de fatos e acontecimentos sociais que engendram o gênero notícia.

Contudo, haja vista que o horizonte temático dos gêneros não está apenas e exclusivamente relacionado e perpassado pela noção de assunto, objetiva-se, nesta seção, não somente apresentar a incidência predominante de assuntos das notícias selecionadas para a pesquisa como, em adição, identificar as diversas relações dialógicas que se entrecruzam no funcionamento desse gênero nos jornais, posto que,

\begin{abstract}
O texto é uma realidade imediata [...]. São pensamentos sobre pensamentos, vivências das vivências, palavras sobre palavras, textos sobre textos. [...] As relações dialógicas entre textos e no interior de um texto. Sua índole específica (não linguistica). Diálogo e Dialética. [...] Não há e nem pode haver textos puros [...]. Por trás de cada texto está o sistema da linguagem. A esse sistema corresponde tudo o que é repetido e reproduzido e tudo o que pode ser repetido e reproduzido, tudo o que pode ser dado fora de tal texto (o dado). Concomitantemente, porém, cada texto (como enunciado) é algo individual, único e singular, e nisso reside todo o seu sentido [...]. (BAKHTIN, 2003, p. 309-310).
\end{abstract}

\title{
4 As relações dialógicas: os discursos, os sentidos e a valoração
}

O horizonte temático do gênero está orientado para e pelos sentidos que se entrecruzam - os outros enunciados; os enunciados do outro - o que se relaciona ao engendramento das relações dialógicas no funcionamento dialógico das notícias. O gênero notícia nos jornais analisados engendra-se em espaços dialógicos constituídos por meio da confluência entre (a) enunciados de outros gêneros na sua materialização enunciativodiscursiva; (b) enunciados de outros gêneros que se intercalam na sua construção textual; (c) enunciados de outros gêneros que se entrecruzam na seção na qual é publicado; (d) gêneros em diferentes seções do jornal que dialogam; (e) notícias que dialogam na seção; (f) notícias que dialogam em diferentes dias de publicação no mesmo jornal e (g) notícias que dialogam em jornais diferentes.

Quanto ao dialogismo constituído por meio da confluência entre enunciados de diferentes gêneros que se engendram na materialidade enunciativo-discursiva da notícia, podemos observar que enunciados de gêneros como a entrevista pingue-pongue ou face-aface ${ }^{\mathrm{iii}}$, o resumo e a biografia são enunciados recorrentes que consubstanciam a construção 
textual das notícias. Em síntese, a partir da análise do corpus selecionado, podemos observar que o gênero notícia pode ser caracterizado por: (1) notícias engendradas por entrevistas; (2) notícias engendradas por biografias e (3) notícias engendradas por resumos de pesquisas. Ambos engendramentos podem ser considerados estratégias dialógicas de construção das notícias no jornalismo impresso.

A respeito dos gêneros que se intercalam na construção textual do gênero notícia, podemos considerar que diversos gêneros (listas, quadros, entre outros) se entrecruzam nesse gênero. O que se observa é que, quanto aos gêneros que se intercalam na construção lingüistco-textual, várias podem ser as possibilidades. No corpus selecionado, os gêneros que se intercalaram à composicionalidade lingüistico-textual foram: a lista de aprovação, o quadro de perguntas-respostas; o mapa, a fotografia, o artigo assinado, a entrevista, a tabela e o infográfico, o que não exclui a possibilidade de intercalação de outros gêneros nas notícias em outro período de circulação.

Sobre os diversos gêneros que dialogam nas seções analisadas, pode-se observar que nos diferentes jornais, são diferentes os gêneros ${ }^{\text {iv }}$ que se entrecruzam dialogicamente. No jornal Zero Hora, a seção 'Geral’ é frequentemente construída com a apresentação do gênero notícia em confluência com os gêneros ${ }^{\mathrm{v}}$ : publicidade, propaganda, gêneros do âmbito da publicação legal (edital, licitação, retificação, comunicado ou notificação), anúncio e reportagen, coluna de participação social, coluna de informe (congressos, eventos e cursos) e coluna da previsão do tempo.

No Correio do Povo, tem-se a recorrência de gêneros como: publicidade, propagada, anúncio, informe (congressos, eventos e cursos) e gêneros do âmbito da publicação legal. Quanto ao O Estado de S. Paulo, podemos visualizar gêneros como publicidades, propagandas, anúncios, coluna da previsão do tempo, coluna/carta de pergunta-resposta, quadro da loteria e informes fúnebres (notas de falecimento).

Acerca do Diário Catarinense, observamos a recorrência dos gêneros publicidade, propaganda, anúncio, gêneros do âmbito da publicação legal e quadro da loteria.

Quanto a enunciados de outros gêneros publicados em outras seções do jornal e que dialogam com a notícia, podemos citar o gênero chamada de capa ${ }^{\mathrm{vi}}$. Esse gênero possui relação íntima de sentido com a notícia, à medida que se entrelaça a esse gênero e apresenta sua funcionalidade a ele subordinada. As chamadas de capa servem como indicadores de localização e persuasão, isto é, direcionam os leitores para determinadas páginas e/ou seções dos jornais, indicando determinadas notícias e convencendo-os a ler. 
Além disso, as chamadas de capa ${ }^{\text {vii }}$ provocam reações de convencimento para a leitura, posto que nem todas as notícias possuem chamadas de capa, apenas as que foram categorizadas como destaque (valoradas como notícias de destaque no jornal do dia). Quanto às relações dialógicas entre notícias na mesma seção, podemos destacar exemplos como:

Ex.1: A notícia Proteção para raios UVA e UVB ( $\left.\mathrm{CP}^{\mathrm{viii}} 01\right)$ dialoga com a notícia Temperaturas amenas neste verão (CP05), ambas possuem temáticas afins.

Ex.2: A notícia Presidente do TJRS faz 'maratona' (CP10) possui relações de diálogo com a notícia Abreu Lima da Rosa deverá assumir comando (CP02) assim como com a notícia Vigília de servidores da Justiça (CP03).

Quanto às relações dialógicas entre notícias publicadas em dias diferentes no mesmo jornal, podemos destacar:

Ex.1: A notícia Cotas exigem mais vagas na UFSC ( $\mathrm{DC}^{\mathrm{ix}} 03$ ), publicada no dia 14 de dezembro de 2007, dialoga com a notícia Liminar que mandava abrir mais vagas na UFSC é suspensa (DC04) publicada dia 19 de dezembro de 2007.

Ex.2: A notícia Justiça libera parte da fortuna da Mega-Sena (DC10), publicada no dia 14 de dezembro de 2007, dialoga com a notícia Todo prêmio da Mega-Sena está bloqueado (DC05) publicada no dia 19 de dezembro de 2007.

Em relação às notícias que dialogam em diferentes jornais, podemos destacar:

Ex.: A notícia Interditado shopping de Law na 25 (OES $\left.{ }^{\mathrm{x}} \mathrm{P} 06\right)$, publicada no dia 19 de dezembro de 2007 no jornal O Estado de S. Paulo, dialoga com a notícia Shopping 25 de Março é interditado (DC06), publicada no mesmo dia no jornal Diário Catarinense.

Observamos, a partir dessa investigação sobre as relações dialógicas da/na notícia, que o dialogismo nesse gênero se constrói por meio do: (a) entrecruzamento de enunciados de diferentes gêneros na construção enunciativo-discursiva da notícia; (b) confluência entre gêneros na construção textual da notícia; (c) diálogo de diversos gêneros na mesma seção; (e) relação dialógica entre enunciados de gêneros diferentes em seções diferentes; (f) relações dialógicas entre notícias da mesma seção; (g) notícias de diferentes datas de publicação no mesmo jornal que dialogam entre si e (h) notícias de diferentes jornais, que dialogam entre si. 
A partir disso, retomamos as discussões anteriores sobre a situação de interação da notícia, relacionando-as com o dialogismo constitutivo desse gênero, caracterizando não apenas esse gênero, mas, em adição, as seções nas quais circula como sendo ambos (o gênero notícia e a seção) interdiscursivos ${ }^{\mathrm{xi}}$. Interdiscursivos, à medida que se conjugam na construção da notícia e da seção diferentes discursos ideologicamente saturados que entram em tensão e diálogo constante, assim como pela diversidade de discursos axiologicamente constituídos que se cruzam na discursividade das informações noticiadas, apresentando implicita ou explicitamente posicionamentos, orientações e recortes valorativos.

\section{0 projeto discursivo da notícia}

Bakhtin (2003) pontua que o que determina um texto como enunciado ${ }^{x i i}$ é seu projeto discursivo ou intenção e a realização desse projeto. Para o autor, “as inter-relações dinâmica desses elementos, a luta entre eles, que determina a índole do texto”. (BAKHTIN, 2003, p. 308).

È dessa forma que o teórico discute sobre o texto como enunciado como mônada original, à medida que pode refletir todos os textos (no limite) de uma da esfera/campo de sentido e o texto observado sob o panorama extralinguistico, pontuando que "do ponto de vista dos objetivos extralingüisticos, o lingüistico é apenas um meio” (BAKHTIN, 2003, p. 313).

Retomando as considerações de Bakhtin (2003) acerca do panorama extralingüístico e sua relação com os enunciados, pode-se afirmar que o projeto discursivo do gênero notícia está intimamente determinado pelas (a) condições sociais da situação de interação - a relação entre autoria e leitor previsto; (b) pelo objeto do discurso - relevância temática e (c) pela esfera social e suas relações dialógicas com outras esferas - campo de atividade. O projeto discursivo da notícia pode ser considerado como o autor e seu querer-dizer; é a vontade, a intenção a proposição do falante mediada pelo discurso e saturada de posições ideológicas e orientações valorativas. Para Rodrigues (2005, p. 158)

[...] Dois aspectos determinam o texto como enunciado, que são o seu projeto discursivo (o autor e seu querer dizer) e a realização desse projeto (a produção do enunciado vinculado às condições/coerções da situação de interção e a sua relação com os outros enunciados; o dado da situação social de interação, da língua, do gênero, etc.). Sendo que a inter-relação dinâmica entre esses aspectos determina o caráter do texto. O texto visto como enunciado tem uma função ideológica particular $[\ldots]$. 
Nas diversas situações de interação, o autor, tendo em vista seu projeto (intenção), regulariza seu discurso (posto que este se constroi perpassado por outros discursos, por posicionamentos ideológicos e orientações axiológicas), projeta seu leitor (constrói uma visão ou uma posição de leitor ideal, isto é, arquiteta um leitor previsível para seu querer-dizer) e se apropria de sentidos plausíveis e coerentes à situação e seu projeto (sentidos relativos ao seu objeto de discurso).

Quanto ao objeto de discurso, retomamos as considerações apresentadas sobre as diversas especificações temáticas e suas íntrisecas ressonâncias de entrecruzamentos. O tema da notícia conjuga-se ao projeto do autor, pois ambos funcionam em mútua dependência, posto que o autor ao determinar seu objeto de discurso, arquiteta seu projeto (especifica sua(s) intenção(ões)) e projeta o seu leitor previsto, objetivado. Dessa inter-relação constitutiva se constrói o querer-dizer do sujeito autor ligado a condições sociais, ideológicas e tensões valorativas do próprio gênero em que se insere.

Além disso, o projeto discursivo está, em adição, ligado à esfera social ou às relações que a esfera social mantém com outros campos. A notícia inserida no campo do jornalismo pode sofrer cruzamentos de outros campos de atividades, como a esfera da publicidade, da política, da justiça, da educação, da religião, entre outras. Dessas esferas, a notícia recupera sentidos, posições que se engendram na apresentação das informações no gênero. É sob esse panorama que a notícia constrói determinados efeitos de sentido delineados e determinados pelo seu projeto discursivo.

Sob essa perspectiva, podemos repensar e questionar qual, de fato, é a intenção ou a finalidade discursiva do gênero notícia na mídia impressa. Qual sua relevância social na sociedade contemporânea e qual seu papel de mediador das diversas situações de interação; qual o objetivo dos jornais em publicar diariamente notícias. Essas questões podem ser discutidas a partir da reflexão sobre a imprensa, o discurso e as influências midiáticas.

Indaga-se, frequentemente, se as mídias possuem influência sobre a opinião pública, se as notícias influenciam no posicionamento e nas orientações ideológicas de seus leitores ou se a instância jornalística é, de fato, uma instituição de manipulação. Pergunta-se, qual a função da notícia nas nossas relações e representações sociais cotidianas. Charaudeau (2006) discute essas questões, afirmando que, geralmente, apontam-se reflexões diretas para o trabalho da mídia, sem qualquer reflexão ou conscientização sobre como sujeitos leitores, ouvintes ou telespectadores se utilizam das informações provinientes dos diversos veículos de comunicação. 
Segundo o autor, o foco está unidirecional, isto é, as discussões estão apenas voltadas ao trabalho das mídias, sem qualquer questionamento acerca das instâncias de recepção. Charaudeau (2006, p. 252) considera que,

\begin{abstract}
Para que haja manipulação, é preciso que alguém (ou uma instância) que tenha a intenção de fazer crer a outro alguém (ou uma outra instância) alguma coisa (que não é necessariamente verdadeira), para fazê-lo pensar (ou agir) num sentido que traga proveito ao primeiro; além disso, é preciso que esse outro entre no jogo sem que o perceba. Ora, não se pode dizer que as coisas acontecem exatamente assim entre as mídias e os cidadãos. Não se pode dizer que os primeiros tenham a vontade de enganar os demais, nem que estes engulam todas as informações que lhe são dadas sem nenhum espírito crítico.
\end{abstract}

Assim, podemos verificar que o projeto discursivo do autor, assim como seu objeto de discurso estão inter-relacionados e determinados seja pela situações de interação imediata e ampla, isto é, em função dos próprios participantes da interação, seja em função de aspectos culturais, históricos, ideológicos ${ }^{\text {xiii }}$ que configuram a própria interação e a esfera na qual o gênero notícia se constitui e funciona. Com isso, retomamos Bakhtin (2000, p. 300-301) para entender que o projeto sociodiscursivo da notícia é reenunciar acontecimentos atuais da vida social, isto é, noticiar os fatos da atualidade de interesse do leitor e da empresa jornalística da qual o jornal pertence.

\title{
Considerações finais
}

A presente pesquisa realizou uma análise descritivo-interpretativa do gênero do discurso notícia da esfera do jornalismo impresso. Buscamos identificar e interpretar as regularidades do gênero, partindo de sua dimensão verbal (linguístico-textual), procurando não apenas compreender sua constituição discursiva, como, em adição, seu funcionamento social.

Por meio da investigação sobre a dimensão verbal da notícia, demonstramos como este gênero se constrói discursivamente por determinados recursos que relativamente se estabilizam no estilo, no tema e na composicionalidade. Retomamos, contudo, que essa proposta metodológica de análise das dimensões se justifica somente para fins de pesquisa, à medida que ambas as dimensões - social e verbal - possuem caráter indissolúvel na materialização concreta do enunciado.

Outra questão que se recupera nessas considerações é o fato de que uma análise de gênero sob a perspectiva da ADD não apresenta categorias pré-estabelecidas; o tratamento 
investigativo sobre gêneros sob o escopo da ADD requer do pesquisador um caminho exaustivo de "idas e vindas” acerca do corpus, haja vista seu caráter heterogêneo, polifônico, pluriestilístico, interdiscursivo e dialógico.

As regularidades dos gêneros surgiram a cada leitura, a cada exploração, a cada reflexão sobre o corpus, impossibilitando a aplicação/reprodução de regularidades de gêneros outros para o gênero em investigação. Cada gênero do discurso assenta-se em um cronotopo, em uma rede social e em situações de interação singulares, construindo-se a partir de caracterizações próprias. Dessa forma, as regularidades enunciativo-discursivas apresentadas nesta pesquisa sob o âmbito da notícia são diferentes das regularidades do gênero artigo assinado (RODRIGUES, 2001) ou do gênero entrevista pingue-pongue (SILVA, 2007), por exemplo.

Além disso, a presente dissertação pode suscitar novas pesquisas, tais como: (a) uma análise de discurso das notícias em determinados jornais impressos ou online sob a perspectiva epistemológica da ADD; (b) um estudo comparativo entre as regularidades do gênero notícia de jornais impressos e jornais virtuais; (c) uma análise de imagens (fotografias e/ou infográficos) sob o âmbito da ADD; (d) um estudo aplicado sobre a didatização do gênero jornalístico notícia, entre outras possibilidades de investigações em Lingüística, Lingüística Aplicada ou em áreas afins.

A partir disso, a pesquisa contribui para a consolidação de uma Análise Dialógica de Discurso (ADD) e de uma Teoria Dialógica de Gêneros do Discurso, ambas sob a perspectiva epistemológica do Círculo de Bakhtin. Em adição, procuramos apresentar um trabalho que se enquadrasse na rede dialógica de pesquisas em Lingüística Aplicada, cujo foco fosse a relação transdisciplinar de diferentes áreas para compreensão de um determinado objeto.

Em conclusão, por meio do estudo sobre a notícia, a presente investigação percorreu caminhos diversos que em confluência viabilizaram um atravessamento axiológico de conceitos, relações e sentidos e cujos resultados não apenas demonstraram a heterogeneidade e fluidez dos gêneros, dentre eles a notícia, como, em adição, reforçaram o postulado bakhtiniano da natureza dialógica da linguagem.

\footnotetext{
${ }^{\mathrm{i}}$ Os dados aqui identificados são extensivamente discutidos em pesquisa prévia.

${ }^{\text {ii }}$ Frente às diversas discussões sobre a autoria das obras de Mikhail Bakhtin, concorda-se com Faraco (2006, p. 57), “ora, diante da teorização de Bakhtin sobre a autoria - que transforma o autor em posições autorais passamos a dispor de um argumento para sugerir que todos os textos disputados foram escritos, de fato, por Bakhtin [...]”. Dessa forma, nesta pesquisa, optamos por delegar a Mikhail Bakhtin as posições autorais das obras estudadas.
} 
iii A respeito da consideração da entrevista pingue-pongue e da entrevista face a face como dois gêneros distintos, ver Silva (2007).

${ }^{\text {iv }}$ Não serão apresentadas discussões exaustivas sobre cada enunciado de gênero que se encontra nas seções dos jornais investigados.

${ }^{\vee}$ Esta pesquisa considera tais gêneros como gêneros do jornal e não gêneros jornalísticos.

vi “A chamada é um dos mais importantes textos do jornal: o seu conjunto é vitrine de cada edição, e tem os maiores índices de leitura. A chamada precisa ao mesmo tempo atrair a atenção do leitor para as páginas internas e construir informação completa em si [...]” (MANUAL DE REDAÇÃO E ESTILO DE O GLOBO, 1997, p. 57).

vii Benites (2001, p. 211) propõe que “a chamada de primeira página do jornal, se propõe a orientar a visão do leitor, através da condensação de grandes quantidades de informação, da seleção e da supressão de dados e, especialmente, da hierarquização dos acontecimentos. Por sua natureza heterogênea, a chamada de primeira página tem um papel fundamental na composição da imagem da realidade pelos leitores. Tanto isso é verdade que [...] quando se quer dar uma idéia do que ocorreu em um determinado momento, é comum se reproduzir somente a capa de um grande jornal. Seu texto exige frases curtas, secas, substantivas, que dêem ao leitor uma idéia de completude, mas, ao mesmo tempo, o remetam para as páginas que trazem a cobertura extensiva, numa premeditada intertextualidade, interna à edição de cada número do jornal”.

viii Jornal Correio do Povo (RS).

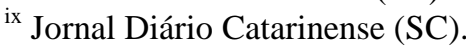

${ }^{x}$ Jornal O Estadão.

${ }^{x i}$ Compreende-se por interdiscursividade que "o dialogismo é sempre entre discursos. O interlocutor só existe enquanto discurso. Há, pois, um embate de dois discursos: o do locutor e do interlocutor, o que significa que o dialogismo se dá sempre entre discursos” (FIORIN, 2006, p. 166).

xii “As noções de enunciado/enunciação têm papel central na concepção de linguagem que rege o pensamento bakhtiniano [...]. Bakhtin e seu círculo, à medida que elaboraram uma teoria enunciativo-discursiva da linguagem, propõem, em diferentes momentos, reflexões acerca de enunciado/enunciação, de sua estreita vinculação com o signo ideológico, palavra, comunicação, interação, gêneros discursivos, texto, tema e significação, discurso, discurso verbal, polifonia, dialogismo [...] e demais elementos constitutivos do processo enunciativo-discursivo" (BRAIT \& MELO, 2006, p. 65).

xiii “ $O$ trabalho da ideologia e dos índices sociais de valor se manifestam não só nos 'conteúdos’ dos enunciados, mas nos gêneros e na sua circulação social diferenciada, demonstrando a existência de diferentes condições sociais de investimento dos gêneros”. (RODRIGUES, 2005, p. 171).

\section{Referências}

ALSINA, M. R. La construcción de la noticia. Barcelona: Paidós, 1993.

BAKHTIN, M. M.; VOLOSCHINOV, V. N. Discurso na Vida e Discurso na Arte (sobre a poética sociológica).Trad. de Carlos Alberto Faraco \& Cristóvão Tezza [para fins didáticos]. Versão da língua inglesa de I. R. Titunik a partir do original russo, 1926.

. (Voloshinov). Marxismo e filosofia da linguagem: problemas fundamentais do método sociológico na ciência da linguagem. 3. ed. São Paulo: Hucitec, 1981.

Problems of Dostoevsky's poetics. Edited and translated by Caryl Emerson. Minnesota: UMP, 1989.

. Para uma filosofia do ato. Texto completo da edição americana Toward a philosophy of the Act. Trad. Carlos Alberto Faraco e Cristóvão Tezza. Austin: University of Texas Press, 1993. 

1998.

Questões de literatura e de estética: teoria do romance. 4. ed. São Paulo: UNESP,

. Os gêneros do discurso. In: BAKHTIN, M. A estética da criação verbal. São Paulo: M. Fontes, 2000. p. 279-326.

Problemas da poética de Dostoiévski. Trad. Paulo Bezerra. 3. ed. Rio de Janeiro: Forense Universitária, 2002.

Estética da criação verbal. 4. ed. São Paulo: M. Fontes, 2003.

(Voloshinov). Marxismo e filosofia da linguagem: problemas fundamentais do método sociológico na ciência da linguagem. 12. ed. São Paulo: Hucitec, 2006.

BENITES, S. A. L. A História contada nas páginas dos jornais. Revista de Letras, n. 5, p. 197-219, jan./jun.2001. Disponível em:

$<$ http://calvados.cs3sl.ufpr.br/ojs2/índex.php/letras/article/view. Acesso em 18 jul. 2007.

BRAIT, B. Bakhtin: outros conceitos-chave. São Paulo: Contexto, 2006.

\& MELO, R. Enunciado/enunciado concreto /enunciação. In: Bakhtin: conceitos-chave. São Paulo: Contexto, 2006.

BRETON, P. A Argumentação na comunicação. Bauru: EDUSC, 2003.

CHARAUDEAU, P. Discurso das mídias. São Paulo: Contexto, 2006.

CORNU, D. Ética da informação. Bauru: EDUSC, 1998.

FARACO, C. A. Autor e autoria. In: BRAIT, B. Bakhtin: conceitos-chave. São Paulo: Contexto, 2006.

FIORIN, J.L. Introdução ao pensamento de Bakhtin. São Paulo : Ática, 2006.

FONTCUBERTA, M. La notícia: pistas para percebir el mundo. Barcelona : Paidós Ibérica, 1993

KATZ, E. Os acontecimentos midiáticos - o sentido da ocasião. In: TRAQUINA, N. Jornalismo: questões, teorias e estórias. Lisboa: Veja, 1993. p. 52-60.

LAGE, N. Estrutura da notícia. São Paulo: Ática, 2005.

O GLOBO. Manual de redação e estilo de O Globo. Luiz Garcia, 24. ed. Rio de Janeiro: Globo, 1997.

RODRIGUES. R. H. A Constituição e funcionamento do gênero jornalístico artigo: Cronotopo e Dialogismo. Tese (Doutorado em Lingüística Aplicada e Estudos da Linguagem - LAEL) - Pontifícia Universidade Católica de São Paulo, São Paulo: PUCSP, 2001. 
.Os gêneros do discurso na perspectiva dialógica da linguagem: A abordagem de Bakhtin. In: MEURER, J. L; BONINI, A. \& MOTTA-ROTH, D. Gêneros: teorias, métodos e debates. São Paulo: Parábola, 2005. p. 152-183.

ROJO, R. Gêneros do Discurso e Gêneros Textuais: Questões Teóricas e Aplicadas. IN: MEURER, J.L.; BONINI, A.; MOTTA-ROTH, D. (orgs.). Gêneros: teorias, métodos e debates. São Paulo: Parábola Editorial. 2005. p. 184-207.

Gêneros do discurso no Círculo de Bakhtin : ferramentas para análise transdisciplinar de enunciados em dispositivos e práticas didáticas. SIGET, 4, 2007, Tubarão: UNISUL, 2007.

SILVA, N. O gênero entrevista pingue-pongue: reenunciação, enquadramento e valoração do discurso do outro. Dissertação (Mestrado PGL) - Universidade Federal de Santa Catarina, Florianópolis, 2007.

TRAQUINA, N. O estudo do jornalismo no século XX. São Leopoldo, RS: Editora UNISINOS, 2001.

\section{Anexo 1}

